\title{
Isomeric Di-C-glycosylflavones in Fig (Ficus carica L.)
}

Fred Siewek and Karl Herrmann

Institut für Lebensmittelchemie der Universität Hannover, Wunstorfer Str. 14, D-3000 Hannover 91

and Lutz Grotjahn and Victor Wray

Gesellschaft für Biotechnologische Forschung, Mascheroder Weg 1, D-3300 Braunschweig

Z. Naturforsch. 40 c, 8-12 (1985); received September 6, 1984

Apigenin-di-C-glycosides, Isolation, Identification, Quantitative Determination, Ficus carica

Two isomeric C-glycosides of apigenin (apigenin-6-C-glucosyl-8-C-arabinoside (schaftoside), apigenin-6-C-arabinosyl-8-C-glucoside (isoschaftoside)) were isolated from leaves of Ficus carica with preparative HPLC.

The glycosides were identified by UV-, ${ }^{1} \mathrm{H}-\mathrm{NMR}$-, ${ }^{13} \mathrm{C}-\mathrm{NMR}$-spectroscopy and FAB-MS.

Their concentration in fruits and leaves were determined by gradient HPLC on reversed phase material.

\section{Introduction}

There is only a little known about the flavonoids of fig (Ficus carica). We know only of one work which deals with the anthocyanin content of the fruit [1]. During our investigation of grape juice adulteration we found two C-glycosides in figs (Scheme 1).<smiles>[R]c1c(O)c([R])c2oc(-c3ccc(O)cc3)cc(=O)c2c1O</smiles>

Scheme 1. Schaftoside: $R_{1}=\alpha$-L-arabinosyl; $R_{2}=\beta$-D-glucosyl. Isoschaftoside: $R_{1}=\beta$-D-glucosyl; $R_{2}=\alpha$-L-arabinosyl.

This paper reports the isolation, identification and quantitative determination of the two flavonoids.

\section{Materials and Methods}

\section{Plant material}

Air dried fig leaves from Egypt were taken for the isolation of flavonoids by preparative HPLC.

Quantitative determination of the glycosides was performed also for leaves of turkish and french figs

Reprint requests to Dr. K. Herrmann.

0341-0382/85/0100-0008 \$01.30/0 as well as for fig fruits of different origins (Brasil, Libya, Israel).

\section{Isolation of the apigenin-di-C-glycosides}

Leaves $(240 \mathrm{~g})$ were homogenized in methanol (21) using a mixer and a ultra-turrax. After extraction for $30 \mathrm{~min}$ at $40^{\circ} \mathrm{C}$ the plant pulp was filtered and the extraction was repeated for a second time. The combined extracts were evaporated at $40{ }^{\circ} \mathrm{C}$ to about $50 \mathrm{ml}$ in vacuo. Both glycosides were separated from the extract by preparative HPLC.

Apparatus: Preparative HPLC system LCX (Philips), injection valve: Rheodyne 7125 with $2 \mathrm{ml}$ sample loop, detection: UV $333 \mathrm{~nm}$, solvent: I. 15\% acetonitrile in $1 \%$ acetic acid, II. $38 \%$ methanol in $1 \%$ acetic acid, flow: $14 \mathrm{ml} / \mathrm{min}$, column: $250 \times$ $16 \mathrm{~mm}$, LiChrosorb RP-18, $10 \mu \mathrm{m}$ (Chrompack).

The fractions containing the $\mathrm{C}$-glycosides were collected and lyophylisated. The purity of the compounds was checked by analytical HPLC.

A second run with a methanol containing liquid phase was necessary to obtain a complete separation of the isomeric flavonoids.

\section{Chemical identification}

Time controlled enzymatic hydrolysis by means of a technical enzyme mixture often allows the determination of the molecular structure (partial hydrolysis) and the determination of the identity and ratio of the hydrolysis products (complete hydrolysis) [2]. 
In the case of the isolated fig-flavonoids no hydrolysis was observed.

\section{UV-spectroscopy}

UV-spectra in methanol, after addition of shiftreagents [3], were recorded with a SP 8-500 UV/VIS spectrophotometer (Philips).

\section{NMR-spectroscopy}

${ }^{1} \mathrm{H}$ and ${ }^{13} \mathrm{C}$ NMR spectra were recorded at ambient temperature on a Bruker AM 300 NMR spectrometer, operating at 300 and $75 \mathrm{MHz}$ respectively, with DMSO- $\mathrm{d}_{6}$ as solvent. Chemical shifts are reported in $\delta$ values (ppm) relative to TMS and coupling constants in $\mathrm{Hz}$.

\section{FAB-MS}

Negative ion mass spectra were recorded on a Kratos MS $50 \mathrm{~S}$ spectrometer with a Kratos FAB source. A Xenon atom gun was used at $9 \mathrm{KV}$. Glycerol was taken as matrix.

Table I. UV-spectral data for apigenin-6-C- $\beta$-D-glucopyranosyl-8-C- $\alpha$-L-arabinopyranoside and its isomer.

\section{Apigenin-di-C-glycosides}

\begin{tabular}{ll}
\hline $\mathrm{MeOH}$ & 269,333 \\
$\mathrm{NaOMe}$ & $234 \mathrm{sh}, 285,334,400$ \\
$\mathrm{AlCl}_{3}$ & $267 \mathrm{sh}, 281,307,351,378 \mathrm{sh}$ \\
$\mathrm{AlCl}_{3} / \mathrm{HCl}$ & $265 \mathrm{sh}, 282,306,347,380 \mathrm{sh}$ \\
$\mathrm{NaOAc} / \mathrm{H}_{3} \mathrm{BO}_{3}$ & $281 \mathrm{sh}, 287,322,342 \mathrm{sh}, 392 \mathrm{sh}$
\end{tabular}

\section{Quantitative determinations}

The quantitative determinations were performed with: HPLC system LCX (Philips), injection valve: Rheodyne 7125 with $10 \mu \mathrm{l}$ sample loop, column: $250 \times 4.6 \mathrm{~mm}$, Shandon ODS-Hypersil, $5 \mu \mathrm{m}$ (Gynkotek), detector: UV $333 \mathrm{~nm}, 1040$ A HP (diode-array-detector) with HP 85 and HP $82901 \mathrm{M}$ flexible disc drive (Hewlett Packard), integrator: HP 3390 A (Hewlett Packard), solvent: A) $1 \%$ acetic acid, B) acetonitrile, $5 \% \mathrm{~B}$ in $\mathrm{A}$ to $30 \% \mathrm{~B}$ in $\mathrm{A}$ in $45 \mathrm{~min}$, flow: $0.8 \mathrm{ml} / \mathrm{min}$.

\section{Results and Discussion}

The compounds isolated were non-hydrolysable which suggested a C-glycosidic structure. Both glycosides showed identical ultravisible spectra, which is possible when both consist of identical aglycones with the same glycosidic linkage positions. The UV-spectrum in methanol showed typical absorptions for flavone glycosides (apigenin) (Table I, [3]).

The structures of the two compounds were readily identified from their ${ }^{1} \mathrm{H}$ - and ${ }^{13} \mathrm{C}$-NMR spectra. In each case only five aromatic protons were observed of which four were part of an $\mathrm{AA}^{\prime} \mathrm{BB}^{\prime}$ spin system (schaftoside: $\mathrm{H}-2^{\prime}, 6^{\prime} 8.01$; $\mathrm{H}-3^{\prime}, 5^{\prime} 6.90 \mathrm{ppm}$; isoschaftoside: $\mathrm{H}-2^{\prime}, 6^{\prime} 8.10, \mathrm{H}-3^{\prime}, 5^{\prime} 6.91 \mathrm{ppm}$ ) and an isolated singlet for $\mathrm{H}-3$ (schaftoside: 6.77; isoschaftoside: $6.78 \mathrm{ppm}$ ).

These data were compatible with the substitution pattern of apigenin-6,8-di-C-glycoside.

Doublets were observed for the anomeric sugar protons with ${ }^{3}(\mathrm{H}, \mathrm{H})$ values characteristic of the

Table II. ${ }^{13} \mathrm{C}-\mathrm{NMR}$ data of both $\mathrm{C}$-glycosides in DMSO-d6. $\mathrm{A}=$ isoschaftoside, $\mathrm{B}=$ schaftoside.

\begin{tabular}{|c|c|c|c|c|c|c|c|c|c|}
\hline & C-2 & C-3 & C-4 & C-5 & C-6 & C-7 & C-8 & C-9 & C-10 \\
\hline A & 163.54 & 102.50 & 181.76 & 158.17 & 108.27 & 162.60 & 104.68 & 155.04 & 102.89 \\
\hline \multirow[t]{2}{*}{$\mathrm{B}$} & 163.43 & 102.09 & 181.76 & 159.39 & 108.36 & 162.78 & 104.20 & 154.29 & 102.72 \\
\hline & $\mathrm{C}-1^{\prime}$ & C-2' & C- $-3^{\prime}$ & C- $4^{\prime}$ & C- $-5^{\prime}$ & C- $6^{\prime}$ & C-1" & C-2" & C- $3^{\prime \prime}$ \\
\hline A & 121.63 & 129.30 & 115.74 & 160.83 & 115.74 & 129.30 & 73.55 & 71.00 & 78.48 \\
\hline \multirow[t]{2}{*}{$\mathrm{B}$} & 121.20 & 128.30 & 115.77 & 160.85 & 115.77 & 128.80 & 73.48 & 70.76 & 78.53 \\
\hline & C-4" & C-5" & C-6" & C-1"'" & C-2"'” & C- $3^{\prime \prime \prime}$ & C-4"'” & C-5"' & \\
\hline A & 70.04 & 81.64 & 61.15 & 73.95 & 68.44 & 74.26 & 69.15 & 70.46 & \\
\hline B & 70.03 & 81.13 & 60.78 & 72.40 & 68.65 & 74.94 & 68.97 & 70.55 & \\
\hline
\end{tabular}



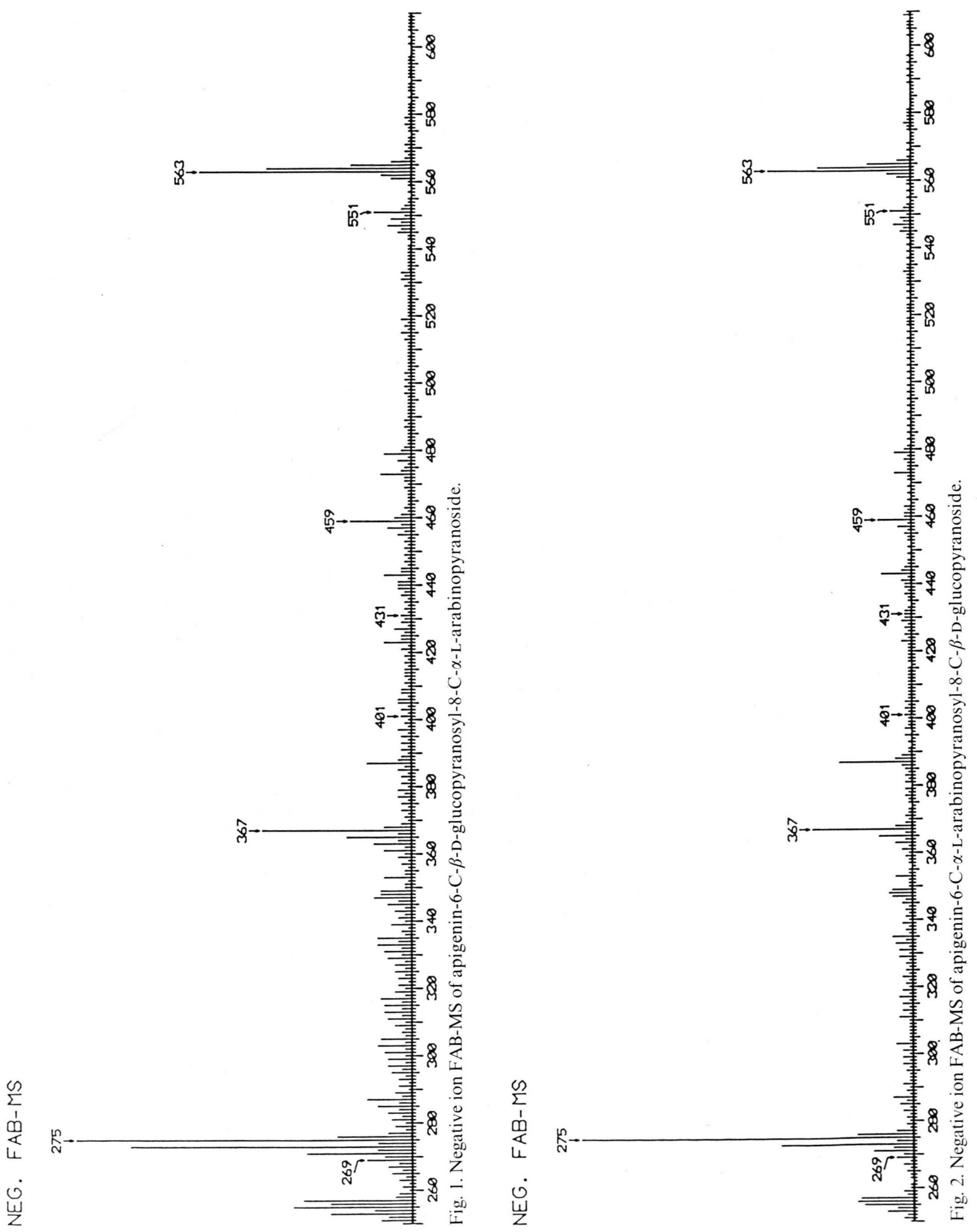


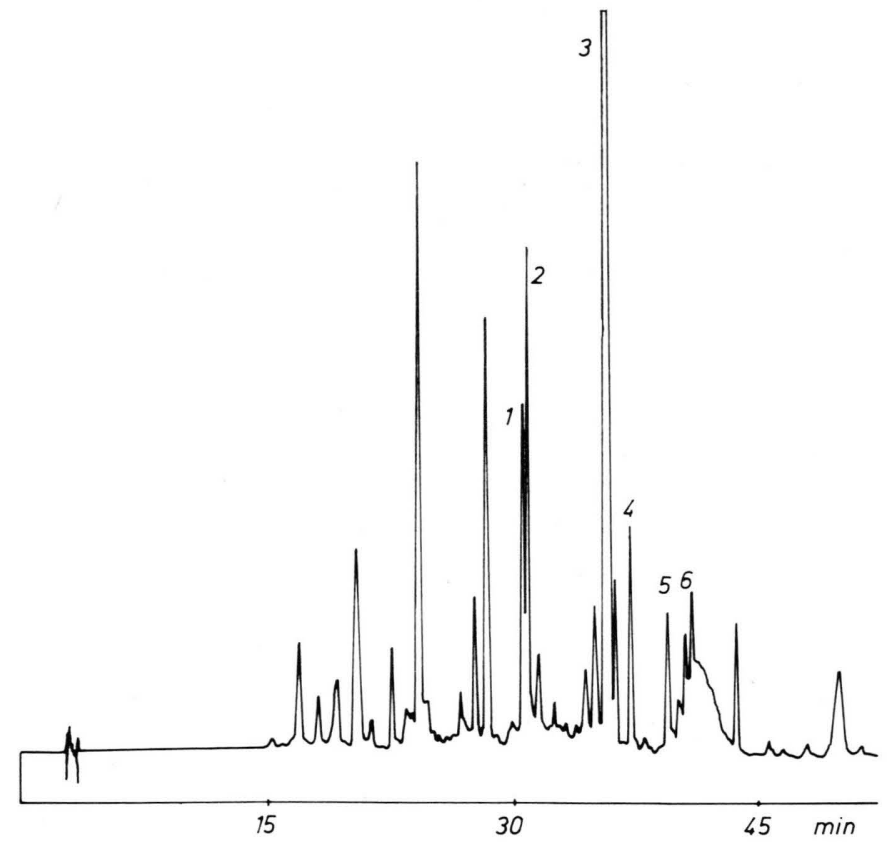

Fig. 3. HPLC chromatogram of fig fruits. $1=$ apigenin-6-C- $\alpha$-L-arabinopyranosyl-8-C- $\beta$-D-glucopyranoside, 2 = apigenin-6-C- $\beta$-D-glucopyranosyl-8$\mathrm{C}$ - $\alpha$-L-arabinopyranoside, $3=$ quercetin-3-O-rutinoside, 4 = quercetin-3-O-glucoside, $5=$ kaempferol3-O-rutinoside, 6 = kaempferol-3-O-glucoside.
Table III. Concentrations of the C-glycosides in leaves and fruit in $\mathrm{mg} / \mathrm{kg}$.

\begin{tabular}{lllll}
\hline & Origin & Year & Sample & C-glycosides \\
\hline fig-fruits & Brasil & 1983 & I & 4.4 \\
& & & II & 4.5 \\
& Brasil & 1984 & I & 6.7 \\
& Libya & 1983 & I & 5.6 \\
fig-leaves & Israel & 1983 & I & 5.2 \\
& Egypt & 1984 & I & 398 \\
& France & 1984 & I & 550 \\
& Turkey & 1984 & I & 320 \\
\hline
\end{tabular}

$\beta$-D-glucoside and $\alpha$-L-arabinoside configurations (schaftoside: H-1", $\mathrm{H}-1^{\prime \prime \prime} 4.78 \quad(J=8.9), 4.70 \mathrm{ppm}$ $(J=9.7 \mathrm{~Hz})$; isoschaftoside: $\mathrm{H}-1^{\prime \prime}, \mathrm{H}-1^{\prime \prime \prime} 4.77(J=9.4)$, $4.67 \mathrm{ppm}(J=8.2 \mathrm{~Hz}))$.

The ${ }^{1} \mathrm{H}$ noise decoupled ${ }^{13} \mathrm{C}$ NMR spectra showed 11 carbon signals in the sugar region (hexose and pentose) and 15 carbon signals for the aglycone. The number of protons carried by each carbon were determined using the INEPT method [4], which allowed immediate assignment of the primary carbon signals. Signal assignments for both glycosides are given in Table II and are identical with those reported for apigenin-6-C- $\beta$-D-glucopyranosyl8-C- $\alpha$-L-arabinopyranoside [5] and its WesselyMoser rearrangement isomer [6].
These results were confirmed by negative ion FAB mass spectroscopy, a very useful method for the mass spectrometric characterization of conjugates when the sugar and aglycone moieties are bound via oxygen.

As well as intense deprotonated molecular ions characteristic sequence ions are also found in these cases.

The compounds isolated showed identical deprotonated molecular ions $(563 \mathrm{~d})$ but no sequence ions. The masses 275, 367, 459 and $551 \mathrm{~d}$ can be assigned to glycerol adduct ions (matrix). In the case of $\mathrm{O}$-glycosidic structure sequence ions should be detected at 269, 401 and $431 \mathrm{~d}$ (Figs. 1 and 2). Their absence supports the di-C-glycosidic structure of both flavonoids. Both flavonoids can be separated by thin-layer chromatography on cellulose [6]. Their different hRf-values allowed unambiguous distinction between the isomers ( $15 \%$ acetic acid: schaftoside $h R f=46$, isoschaftoside $h R f=34$ ).

The $\mathrm{C}$-glycosides are present in relatively high concentrations in the analyzed fig leaves. Lower, but still considerable amounts, are located in the fruit (Table III, Fig. 3).

These glycosides have already been described in different plants (e.g. Compositae [7, 8], Poaceae [9], Commelinaceae [10], Cyperaceae [11] but not in fig (Moraceae)). 
Furthermore the following flavonol glycosides were identified after co-chromatography in fig fruits: quercetin-3-O-rutinoside, quercetin-3-O-glucoside, kaempferol-3-O-rutinoside, kaempferol-3-Oglucoside.

[1] A. A. Puech, C. A. Rebeiz, P. B. Catlin, and J. C. Crane, J. Food Science 40, 775 (1975).

[2] F. Siewek, R. Galensa, and K. Herrmann, J. Agric. Food Chem. (in press).

[3] T. J. Mabry, K. R. Markham, and M. B. Thomas, The Systematic Identification of Flavonoids, Springer Verlag Berlin, Heidelberg, New York 1970.

[4] G. A. Morris and R. Freemann, J. Amer. Chem. Soc. 101, 760 (1979).

[5] K. R. Markham, V. M. Chari, and T. J. Mabry, in The Flavonoids: Advances in Research, Chapman and Hall, London 1982.

\section{Acknowledgements}

We wish to thank Prof. A. Askar (Ismailia, Egypt), Prof. J. J. Macheix (Montpellier, France), and Dr. L. Tugrul (Izmir, Turkey) for the fig leaves and the Arbeitsgemeinschaft industrieller Forschungsvereinigungen (AIF) and the Arbeitskreis der Ernährungsindustrie for financial support.

[6] B. G. Österdahl, Acta Chem. Scand. B 33, 400 (1979).

[7] J. Raynaud and L. Rasolojaona, Planta Med. 37, 168 (1979).

[8] Y. L. Liu and T. J. Mabry, Rev. Latinoam. Quim. $13(2), 56$ (1982).

[9] H. Wagner, G. Obermeier, V. M. Chari, and K. Galle, J. Nat. Prod. 43 (5), 583 (1980).

[10] M. P. Martinez and T. Swain, Phytochemistry 15, 834 (1976).

[11] M. Salmenkallio, S. McCormick, T. J. Mabry, G. Dellamonica, and J. Chopin, Phytochemistry 21, 2990 (1982). 